\title{
The relationship between health literacy and quality of life among frequent users of health care services: a cross-sectional study

\author{
Éva Marjorie Couture ${ }^{1 *}$ (D) Maud-Christine Chouinard², Martin Fortin ${ }^{1}$ and Catherine Hudon ${ }^{1,3}$
}

\begin{abstract}
Background: Although health literacy and quality of life are important concepts in health care, the link between them is unclear, especially for a population of frequent users of health care services with chronic diseases. Low health literacy is a common problem that has been linked to several negative health outcomes. Quality of life is an important health outcome in patient-centered care. Frequent users of health care services are a vulnerable population that deserves attention due to high costs and negative outcomes such as lower quality of life and higher mortality. The objective of this study was to examine the relationship between health literacy and the physical and mental components of quality of life among frequent users of health care services with chronic diseases.

Methods: This study presents the cross-sectional analysis of data collected through the V1SAGES project, a randomized controlled trial on the effectiveness of a case management intervention in primary care in Quebec, Canada. Participants $(n=247)$ were frequent users of health care services presenting at least one chronic condition. Health literacy was measured by the Newest Vital Sign (NVS), and the physical and mental components of quality of life were evaluated by the Short Form Health Survey Version 2 (SF-12v2). The association between health literacy (independent variable) and the physical and mental components of quality of life was examined using biserial correlation.
\end{abstract}

Results: No association was found between health literacy and quality of life (physical component: $r=0.108, \rho=0.11$; mental component: $r=0.147, \rho=0.15$ ).

Conclusion: This study suggests that there is no relationship between health literacy and the physical and mental components of quality of life among frequent users of health care services.

Trial registration: NCT01719991. Registered October 25, 2012.

Keywords: Frequent users, Primary care, Health literacy, Quality of life, Chronic disease

\section{Background}

Health literacy is an emerging concept that has been growing in importance in the last decades [1-3]. Although there is no consensus on the definition; it remains important considering the great prevalence of low health literacy and its impacts on health [4-9]. The World Health Organization (WHO) defines health literacy as: "the cognitive and social skills which determine the motivation and ability of individuals to gain access

\footnotetext{
* Correspondence: Eva.Marjorie.Couture@usherbrooke.ca

${ }^{1}$ Département de médecine de famille et de médecine d'urgence, Université de Sherbrooke, 3001 12e Avenue Nord, Sherbrooke, Québec J1H 5N4, Canada

Full list of author information is available at the end of the article
}

to, understand and use information in ways which promote and maintain good health" [10].

Low health literacy is highly prevalent in the general population [5], especially in individuals with chronic diseases [8]. Low health literacy can have numerous negative impacts on health and is associated with a decrease in adherence to treatment $[6,9]$ and in use of preventive services [4, 7], an increase in number of hospitalisations $[11,12]$ and health system costs [13], poorer health [7, 14] and higher mortality risk [1, 15]. Health literacy could also be a better health indicator than age, income, employment status and education [16].

The relationship between health literacy and quality of life, an important patient-centered outcome often 
evaluated in studies, [17] is unclear. A study conducted in 2004 in USA $(n=249)$ showed that lower health literacy was associated with poorer quality of life for a population seen at a university-based family teaching clinic [18]. However, various studies on other types of population reported different results. A study by Wang [19] conducted among 913 women living in a rural region of China, showed that a decrease in health literacy was associated to a decrease in quality of life but only for certain ethnic groups. A study by Macabasco-O'Connel [20] also demonstrated that patients suffering from heart failure $(n=605)$ with adequate health literacy had a better quality of life. Song's [21] study among men with prostate cancer ( $n=1581$ ), showed an association only with the mental component of quality of life. Finally, a study by Smith [22] conducted in a Canadian population of 259 adults in primary care, did not demonstrate an association between health literacy and quality of life. In light of these different results, it is possible that the relationship between health literacy and quality of life depends on certain aspects: specific chronic diseases, cultural characteristics or aspects of quality of life.

Frequent users of healthcare services may be one of the groups influenced by health literacy. Frequent users can need $80 \%$ of resources used while they only count for $10 \%$ of the population [23]. They also present more chronic diseases, greater psychological distress, and higher rates of hospitalisation and mortality [24-26]. In this vulnerable population, it was also shown that quality of life may be poorer [27], but no study evaluated the association between health literacy and quality of life. Such an association could prompt the development and implementation of interventions for frequent users of health care services adapted to their level of health literacy [28-30].

The aim of this study was to examine the association between health literacy and the physical and mental components of quality of life among frequent users of health care services with chronic diseases seen in primary care.

\section{Methods}

\section{Setting and design}

This study is a cross-sectional analysis conducted among patients recruited for a larger project, V1SAGES, a randomized controlled trial (RCT) on the effectiveness of a case management intervention by primary care nurses in Family Medicine Groups (FMG) in the Saguenay-LacSaint-Jean region of Quebec (Canada) described in a previous article [31]. A FMG is a primary care organization in which a group of family physicians works closely with nurses in the provision of primary care services to a group of registered patients, including patient follow-up, health promotion and preventive care [32].

\section{Participants}

The participants of V1SAGES were identified by their primary care physician using a software program. First, the case management intervention was presented to all primary care physicians working in the four FMGs, for a total of 38 family physicians. Then, a computerized list of their most frequent users of hospital services was delivered to each family physician, namely patients with more than three visits to the emergency and/or hospitalisations in the previous year. This list was obtained using the MAGIC Chronique software (Médiamed Technologies), an information system technology providing support for decision-making to family physicians. From the computerized list, the family physicians could identify eligible patients they believed would benefit the most from the intervention. They could also recommend patients that were not on the list but were considered as complex because they were frequent users of primary care services. Eligible patients had to be aged between 18 and 85 years and affected by at least one chronic disease (diabetes, cardiovascular disease, respiratory disease, musculoskeletal disease and/or chronic pain). Patients with serious cognitive impairment, severe psychiatric illness or a prognosis of less than one year were excluded.

All participants completed and signed an informed consent form. The study was approved by the research ethics board of the Centre intégré universitaire de santé et de services sociaux (CIUSSS) du Saguenay-Lac-Saint-Jean.

\section{Data collection}

Data from participants were collected at baseline (T0), before their randomization to the case management intervention. A self-administered questionnaire was completed in the presence of a research assistant who provided assistance to the participant, ranging from minimal supervision to reading all the questions, if and when needed. Participants with limitations could complete the questionnaire at home in the presence of a research assistant.

Health literacy was measured by the Newest Vital Sign (NVS) [33]. The NVS consists of a nutrition label from an ice cream container presented to the participant who has to answer six questions about it. It takes approximately three (3) minutes to administer. On a range from zero to six, a score of four or higher is considered as adequate health literacy [33]. The NVS is a reliable instrument presenting a Cronbach alpha $>0.76$ and correlated with the Test of Functional Health Literacy in Adults (TOFHLA), another instrument measuring health literacy $(r=0.59, P<.001)[33,34]$. The NVS demonstrated high sensitivity and moderate specificity for detecting limited literacy and is a markedly better predictor of patients with low literacy than education or age alone [33]. The Quality of life was measured by the SF-12v2 [35], a 
short version of the SF-36 [36]. It includes 12 questions and 8 sub-scales, and is used to calculate two component scores, the Physical Component Summary Score (PCS) and the Mental Component Summary Score (MCS), ranging from 0 to 100 . Both component summary scores demonstrated high reliability with Cronbach alphas $>0.80$ and correlated with the EuroQol five dimensions questionnaire (EQ-5D), another instrument measuring quality of life [37]. The Disease Burden Morbidity Assessment (DBMA) was used to evaluate the illness burden of patients. Using a list of 21 conditions, patients rated the degree to which the condition limits his or her daily activities on a five-point descriptive scale $[38,39]$. The total score is the sum of the degree of limitation for all conditions. The DBMA was validated in a French-speaking population from Quebec and presented a high test-retest reliability (ICC: $0.86,95 \%$ CI: 0.79-0.92) [39]. The questionnaire also included sociodemographic questions (gender, age, education and family income).

\section{Sample size}

As suggested by Tabachnick and Fidell (2007) [40], the desirable minimum $\mathrm{n}$ for testing the significance of individual predictors is $n>104+\mathrm{k}$ (where $\mathrm{k}$ is the number of predictable variables in the regression), based on detecting a medium effect size, with $\alpha<=.05$, and a power of $80 \%$. A minimum sample size of 110 participants was estimated [40]. In the V1SAGES project, 404 patients were identified by the family physicians and contacted to assess eligibility. A total of 247 patients were randomized and were included in this cross-sectional analysis.

\section{Data analysis}

We described the sample using the mean \pm standard deviation (SD) for continuous variables and percentage for categorical variables. A biserial correlation between health literacy (independent variable) and the two component scores (PCS and MCS) of quality of life (dependant variable) was performed. Assumptions of biserial correlation were verified and confirmed by a statistician. Health literacy was considered as a dichotomous variable: adequate (NVS $\geq 4$ ) or not (NVS $<4)$. The two component scores (PCS and MCS) of quality of life were considered as continuous variables. All analyses were performed with PASW Statistics 20 (SPSS Inc.). The $\alpha$ significance level was set at 0.05 .

\section{Results}

A total of 247 participants were included in this study (Table 1). Many patients (44.5\% male, mean age of 62.8 , $\mathrm{SD}=11.8$ years) presented compromised health literacy levels (NVS $<4$ [33], 67.5\%). The mean score for the physical component summary of the SF-12v2 was 37.2, $\mathrm{SD}=11.7$, and the mean score for the mental component summary was $44.6, \mathrm{SD}=12.2$ (Table 2). Most patients presented a high illness burden (DBMA mean 13.4, SD = 8.5) with a mean of six (6) chronic diseases per patient.

In the biserial correlations (Table 3), no association between health literacy and quality of life for the physical component nor the mental component was shown.

\section{Discussion}

This is the first study examining the association between health literacy and physical and mental components of

Table 1 Sample characteristics

\begin{tabular}{|c|c|c|c|c|}
\hline Characteristic & Participants & $\begin{array}{l}\text { Compromised health } \\
\text { literacy (NVS <4), } \mathrm{n}(\%)\end{array}$ & $\begin{array}{l}\text { QOL (SF-12 V2), Physical } \\
\text { component, mean (SD) }\end{array}$ & $\begin{array}{l}\text { QOL (SF-12 V2), Mental } \\
\text { component, mean (SD) }\end{array}$ \\
\hline Mean age (SD), years & $59.9(13.3)$ & & & \\
\hline Male, n (\%) & $102(41.6)$ & & & \\
\hline \multicolumn{5}{|c|}{ Illness burden, mean (SD) 1 missing } \\
\hline DBMA & $13.4(8.5)$ & & & \\
\hline \multicolumn{5}{|l|}{ Education, n (\%) } \\
\hline$<8$ years & $36(14.6)$ & $32(88.9)$ & $37.7(10.9)$ & $41.5(11.7)$ \\
\hline $8-12$ years & $123(49.8)$ & $91(74.0)$ & $36.3(11.8)$ & $44.8(12.4)$ \\
\hline Professional/trade school & $11(4.4)$ & $7(63.6)$ & $36.1(14.8)$ & $41.8(12.4)$ \\
\hline College & $52(21.1)$ & $22(42.3)$ & $38.7(12.5)$ & $45.3(12.0)$ \\
\hline University & $25(10.1)$ & $12(48.0)$ & $38.5(9.8)$ & $48.1(11.1)$ \\
\hline \multicolumn{5}{|c|}{ Family income in CAD, $\mathrm{n}$ (\%) 5 missing } \\
\hline$<10,000 \$$ & $24(9.9)$ & $20(83.3)$ & $35.5(10.7)$ & $37.3(14.1)$ \\
\hline 10,000 to $29,999 \$$ & $79(32.7)$ & $63(79.7)$ & $36.6(12.1)$ & $45.1(12.8)$ \\
\hline 30,000 to $49,999 \$$ & $75(31.0)$ & $47(62.7)$ & $36.5(12.0)$ & $45.5(10.8)$ \\
\hline$\geq 50,000 \$$ & $64(26.4)$ & $29(45.3)$ & $39.3(11.3)$ & $47.0(10.7)$ \\
\hline
\end{tabular}

CAD Canadian dollars, NVS Newest Vital Sign, SF-12v2 Short Form Health Survey, DBMA Disease Burden Morbidity Assessment, SD standard deviation 
Table 2 Patient health literacy levels and PCS and MCS for quality of life

\begin{tabular}{ll}
\hline Variable & Participants \\
\hline Health literacy (NVS), n (\%) 4 missing & \\
NVS $<4$ & $164(67.5)$ \\
NVS $\geq 4$ & $79(32.5)$ \\
QOL (SF-12 V2), mean (SD) & \\
Physical component & $37.2(11.7)$ \\
Mental component & $44.6(12.2)$ \\
\hline
\end{tabular}

NVS Newest Vital Sign, SF-12v2 Short Form Health Survey, SD standard deviation

quality of life in frequent users of health care services with chronic diseases in primary care. Results show the absence of an association between these variables. As mentioned previously, the studies evaluating the association between health literacy and quality of life produced mixed results [18-22]. Populations were diverse in terms of culture and geographic location. No other study targeted frequent users of health care services. Only one study was conducted in primary care and did not show a link between these two variables either [22]. Because the two studies conducted in Canada did not show an association, consideration must be given to the impact of the geographical and cultural situation of participants as a potential explanation for part of the results. It is recognized that culture/ geographical situation may have an impact on quality of life as it is, in part at least, culturally constructed [27].

No other study used the NVS. Health literacy is not a concept that is easily assessed [41] and no tool commands universal agreement [42]. The other studies cited above used a "homemade" questionnaire [19], the TOFHLA [20], the Rapid Estimate of Adult Literacy in Medicine (REALM) or its adaptations [21, 22]. The TOFHLA, REALM (and its adaptations) and the NVS are measurement tools recognized and validated for health literacy [33, 43-45]. Therefore it is unlikely that the different tools used to measure health literacy, alone, were able to explain an absence of association.

In respect to the measurement of quality of life, only one other study used the SF-12v2 [21]. This study, among 1581 participants with a prostate cancer diagnosis, showed a link between health literacy (measured by the REALM) and the mental health component of quality of life. Each of the other studies mentioned above used a different measure of quality of life, such as the

Table 3 Biserial correlations with Newest Vital Sign

\begin{tabular}{lll}
\hline & Correlation coefficient & $P$ value \\
\hline SF-12 V2 & & \\
Physical component & 0.108 & 0.11 \\
Mental component & 0.147 & 0.15 \\
\hline
\end{tabular}

EQ-5D [19], the Heart Failure Symptom Scale (HFSS) [20], the COOP/WONCA Charts [22] or the Healthy Days Core Module (CDC-HRQOL-4) [18]. These tools represents the two main type of approach for measuring quality of life: specific instrument focussing on problems associated with a single disease, patient type, or function; and generic instruments providing health profile applicable for broader type of situation [46].

The SF-36 and its short version, the SF-12, used in this study, are generic tools for the assessment of quality of life [47-49]. Although they are among the most frequently used, no one tool is recognized as the accepted standard to measure quality of life [49]. Again, it would be surprising that the different types of tools used to measure quality of life be able to alone explain the absence of association, especially considering that the presence or absence of an association in the studies cited above, do not seem to depend on the tool used.

This is the first research evaluating the relationship between health literacy and physical and mental components of quality of life among frequent users of health care services. The size of the sample for this type of analysis allows for an adequate statistical power. The study also has its limits. It relied on the secondary analysis of data from the V1SAGES project. The questionnaires were self-administered which may have caused a social desirability bias. Participants may have responded more positively to the questionnaires than what is the real reflection of their situation and thus potentially contribute to results which are partially inaccurate.

Finally, using the NVS to measure health literacy may have resulted in biases. It does not allow us to examine all spheres of health literacy, but relies more on reading skill, reading comprehension and numeracy and its specificity may lead to overestimate the rate of low health literacy [33]. However, it is a recognized tool for health literacy $[41,50]$ and presents an adequate correlation with the TOFHLA [33]. Health literacy remains a concept that is difficult to properly assess and represents a challenge [41]. The NVS was chosen in this study because of its availability in French-language, takes little time to complete while presenting adequate metrological qualities. A future study using more than one measure of health literacy could be considered. It would then be able to use the NVS, a validated French-language version of the TOFHLA and/or another tool for the measure of health literacy concurrently.

The absence of a relationship between health literacy and quality of life in this study does not mean that we should not address the impact of these variables one on the other, but rather that we should attempt to gain a better understanding and evaluate them in order to get an in-depth comprehension of their mutual interrelations. Nevertheless, as described previously, quality of 
life and health literacy are linked to the global health of individuals.

In future research it would be interesting to verify if there is an association between these two variables in frequent users of health care services in general. The definition of frequent user is not clearly defined and varies from one study to another [51]. Results may vary if the cut-off is higher. Finally, a next step would be to look at variation in time for health literacy and quality of life, as well as the effect on the relationships in the course of interventions targeting frequent users or individuals with low health literacy.

\section{Conclusion}

This study did not show an association between health literacy and the physical and mental components of quality of life among frequent users of health care services with chronic diseases in primary care. More research is necessary to see if there is an association for other groups of patients, very frequent users of health care services as well as frequent users not necessarily presenting chronic diseases.

\begin{abstract}
Abbreviations
CAD: Canadian dollars; CIUSSS: Centre intégré universitaire de santé et services sociaux; DBMA: Disease burden morbidity assessment; EQ5D: EuroQol five dimensions questionnaire; ER: Emergency room; FMG: Family medicine group; HFSS: Heart failure symptom scale; HRQOL: Health related quality of life; MCS: Mental component summary score; NAAL: National assessment of adult literacy; NALS: National adult literacy survey; NVS: Newest vital sign; OHIP: Oral health impact profile; PCS: Physical component summary score; RCT: Randomized controlled trial; REALM: Rapid estimate of adult literacy in medicine; SD: Standard deviation: SF-12 V2: Short form health survey version 2; TOFHLA: Test of functional health literacy in adults; WHO: World Health Organization
\end{abstract}

\section{Acknowledgments}

The authors thank Ms. Susie Bernier for her editorial assistance and Ms. Marie-France Dubois for her statistical advice.

\section{Funding}

This research was funded by the Pfizer-FRSQ-MSSS chronic disease fund.

\section{Availability of data and materials}

Data is available on request from the corresponding author.

\section{Authors' contributions}

EMC conceived and elaborated the study and wrote the first version of this manuscript as a student completing a master of science in family medicine under the supervision of MCC, MF and CH. All authors participated in the data analysis as well as read and gave their approval to the final version of this manuscript submitted for publication.

\section{Ethics approval and consent to participate}

The study was approved by the research ethics board of the Centre intégré universitaire de santé et services sociaux (CIUSSS) du Saguenay-Lac-SaintJean. All the participants completed and signed an informed consent form.

\section{Consent for publication}

Not applicable.

\section{Competing interests}

This project is funded by the Pfizer-FRSQ-MSSS chronic disease fund. None of the funding agencies - Pfizer, Fonds de recherche du Québec - Santé
(FRQ-S) or the ministère de la santé et des services sociaux (MSSS) - had any role in preparing, reviewing or approving the manuscript. They will not be involved in the collection, analysis or interpretation of the data.

\section{Publisher's Note}

Springer Nature remains neutral with regard to jurisdictional claims in published maps and institutional affiliations.

\section{Author details}

'Département de médecine de famille et de médecine d'urgence, Université de Sherbrooke, 3001 12e Avenue Nord, Sherbrooke, Québec J1H 5N4, Canada. ${ }^{2}$ Département des sciences de la santé, Université du Québec à Chicoutimi, 555, boulevard de l'Université, Saguenay, Québec G7H 2B1, Canada. ${ }^{3}$ Centre de recherche du Centre hospitalier universitaire de Sherbrooke, 3001 12e Avenue Nord, Sherbrooke, Québec J1H 5N4, Canada.

Received: 15 December 2016 Accepted: 3 July 2017

Published online: 06 July 2017

\section{References}

1. Baker D, Feinglass J, Thomspon J, Gazmararian J, Huang J. Health literacy and mortality among elderly persons. Arch Intern Med. 2007:167:1503-9.

2. Nutbeam D. The evolving concept of health literacy. Soc Sci Med. 2008; 67(12):2072-8

3. Berkman ND, Davis TC, McCormack L. Health literacy: what is it? J Health Commun. 2010:15(Suppl 2):9-19.

4. Cho YI, Lee SY, Arozullah AM, Crittenden KS. Effects of health literacy on health status and health service utilization amongst the elderly. Soc Sci Med. 2008;66(8):1809-16.

5. Kutner M, Greenberg E, Jin Y, Paulsen C, White S. The health literacy of America's adults results from the 2003 National Assessment of adult literacy. Washington: US Department of Education; 2006.

6. Muir KW, Santiago-Turla C, Stinnett SS, Herndon LW, Allingham RR, Challa P, Lee PP. Health literacy and adherence to glaucoma therapy. Am J Ophthalmol. 2006;142(2):223-6.

7. Berkman ND, Sheridan SL, Donahue KE, Halpern DJ, Crotty K. Low health literacy and health outcomes: an updated systematic review. Ann Intern Med. 2011;155(2):97-107.

8. Irwin S, Jungeblut $K$, Jenkins L, Kolstad A. Adult literacy in America a first look at the findings of the National Adult Literacy Survey. Washington: U.S. Department of Education Office of Educational Research and Improvement; 2002.

9. Kalichman SC, Ramachandran B, Catz S. Adherence to combination antiretroviral therapies in HIV patients of low health literacy. J Gen Intern Med. 1999:14(5):267-73.

10. World Healh Organization. Health Promotion Track 2: Health literacy and health behaviour http://www.who.int/healthpromotion/conferences/7gchp/ track2/en/. Accessed December 2016

11. Baker DW, Gazmararian JA, Williams MV, Scott T, Parker RM, Green D, Ren J, Peel J. Functional health literacy and the risk of hospital admission among Medicare managed care enrollees. Am J Public Health. 2002;92(8):1278-83.

12. Baker DW, Parker RM, Williams MV, Clark WS, Nurss J. The relationship of patient reading ability to self-reported health and use of health services. Am J Public Health. 1997;87(6):1027-30.

13. Eichler $K$, Wieser $S$, Brugger $U$. The costs of limited health literacy: a systematic review. Int J Public Health. 2009:54(5):313-24.

14. Wolf MS, Gazmararian JA, Baker DW. Health literacy and functional health status among older adults. Arch Intern Med. 2005;165(17):1946-52.

15. Sudore RL, Yaffe K, Satterfield S, Harris TB, Mehta KM, Simonsick EM, Newman AB, Rosano C, Rooks R, Rubin SM, et al. Limited literacy and mortality in the elderly: the health, aging, and body composition study. J Gen Intern Med. 2006;21(8):806-12.

16. Nardone DA. The crucial link between literacy and health. Ann Intern Med. 2004:141(1):81.

17. Healthy people 2020. Foundation health measure report, Health-related quality of life and well-being 2010. https://www.healthypeople.gov/sites/ default/files/HRQoLWBFullReport.pdf. Acessed July 2017.

18. Wallace $L S$, Rogers $E S$, Weiss BD. Relationship between health literacy and health-related quality of life among Tennesseans. Tenn Med. 2008;101 (5):35-9.

19. Wang C, Li H, Li L, Xu D, Kane RL, Meng Q. Health literacy and ethnic disparities in health-related quality of life among rural women: results from a Chinese poor minority area. Health Qual Life Outcomes. 2013;11:153. 
20. Macabasco-O'Connell A, DeWalt DA, Broucksou KA, Hawk V, Baker DW Schillinger D, Ruo B, Bibbins-Domingo K, Holmes GM, Erman B, et al. Relationship between literacy, knowledge, self-care behaviors, and heart failure-related quality of life among patients with heart failure. J Gen Intern Med. 2011;26(9):979-86.

21. Song L, Mishel M, Bensen JT, Chen RC, Knafl GJ, Blackard B, Farnan L, Fontham E, Su LJ, Brennan CS, et al. How does health literacy affect quality of life among men with newly diagnosed clinically localized prostate cancer? Findings from the North Carolina-Louisiana prostate cancer project (PCaP). Cancer. 2012;118(15):3842-51.

22. Smith $\mathrm{J}$, Haggerty J. Literacy in primary care populations: is it a problem? Canadian J Public health = Revue canadienne de sante publique. 2003;94(6): 408-12.

23. Commission on the Reform of Ontario's Public Services. Public services for Ontarians: a path to sustainability and excellence. Ottawa: Queen's Printer for Ontario; 2012.

24. Althaus F, Paroz S, Hugli O, Ghali WA, Daeppen JB, Peytremann-Bridevaux I, Bodenmann P. Effectiveness of interventions targeting frequent users of emergency departments: a systematic review. Ann Emerg Med. 2011;58(1): 41-52. e42

25. Lucas $\mathrm{RH}$, Sanford $\mathrm{SM}$. An analysis of frequent users of emergency care at an urban university hospital. Ann Emerg Med. 1998;32(5):563-8.

26. Sun BC, Burstin HR, Brennan TA. Predictors and outcomes of frequent emergency department users. Acad Emerg Med Off J Soc Acad Emerg Med. 2003;10(4):320-8.

27. Kersnik J, Svab I, Vegnuti M. Frequent attenders in general practice: quality of life, patient satisfaction, use of medical services and GP characteristics. Scand J Prim Health Care. 2001;19(3):174-7.

28. Wang C, Kane R, Xu D, Meng Q. Health literacy as a moderator of healthrelated quality of life responses to chronic disease among Chinese rural women. BMC Women's Health. 2015;15(1):34.

29. Institute of Medicine. Health literacy: a prescription to end confusion. Washington: The National Academies; 2004.

30. Saha S. Improving literacy as a means to reducing health disparities. J Gen Intern Med. 2006;21(8):893-5.

31. Chouinard MC, Hudon C, Dubois MF, Roberge P, Loignon C, Tchouaket E, Fortin M, Couture EM, Sasseville M. Case management and self-management support for frequent users with chronic disease in primary care: a pragmatic randomized controlled trial. BMC Health Serv Res. 2013;13:49.

32. Ministère de la santé et des services sociaux. Family Medicine Groups http:// www.msss.gouv.qc.ca/en/sujets/organisation/gmf.php. Accessed December 2016.

33. Weiss BD, Mays MZ, Martz W, Castro KM, DeWalt DA, Pignone MP, Mockbee J, Hale FA. Quick assessment of literacy in primary care: the newest vital sign. Ann Fam Med. 2005;3(6):514-22.

34. Hudon C, Fortin M, Poitras ME, Almirall J. The relationship between literacy and multimorbidity in a primary care setting. BMC Fam Pract. 2012;13:33.

35. Ware J Jr, Kosinski M, Keller SD. A 12-item short-form health survey: construction of scales and preliminary tests of reliability and validity. Med Care. 1996;34(3):220-33.

36. Hopman WM, Towheed T, Anastassiades T, Tenenhouse A, Poliquin S, Berger C, Joseph L, Brown JP, Murray TM, Adachi JD, et al. Canadian normative data for the SF-36 health survey. Canadian multicentre osteoporosis study research group. CMAJ. 2000;163(3):265-71.

37. Cheak-Zamora NC, Wyrwich KW, McBride TD. Reliability and validity of the SF12v2 in the medical expenditure panel survey. Qual Life Res. 2009;18(6):727-35.

38. Bayliss EA, Ellis $J \mathrm{~L}$, Steiner JF. Subjective assessments of comorbidity correlate with quality of life health outcomes: initial validation of a comorbidity assessment instrument. Health Qual Life Outcomes. 2005;3:51.

39. Poitras ME, Fortin M, Hudon C, Haggerty J, Almirall J. Validation of the disease burden morbidity assessment by self-report in a French-speaking population. BMC Health Serv Res. 2012;12:35.

40. Tabachnick B, Fidell LS. Using multivariate statistics, 3rd edition edn. New York: HarperCollins Publishers; 1996.

41. Baker DW. The meaning and the measure of health literacy. J Gen Intern Med. 2006;21(8):878-83.

42. DeWalt DA, Hink A. Health literacy and child health outcomes: a systematic review of the literature. Pediatrics. 2009;124(Suppl 3):S265-74.

43. Baker DW, Williams MV, Parker RM, Gazmararian JA, Nurss J. Development of a brief test to measure functional health literacy. Patient Educ Couns. 1999; 38(1):33-42.
44. Parker RM, Baker DW, Williams MV, Nurss JR. The test of functional health literacy in adults: a new instrument for measuring patients' literacy skills. J Gen Intern Med. 1995;10(10):537-41.

45. Shigaki C, Kruse R, Mehr D, Ge B. The REALM vs NVS : a comparison of health literacy measures in patients with diabetes. Annals of behavioral sciences and medical education. 2012;18:9.

46. Guyatt GH, Feeny DH, Patrick DL. Measuring health-related quality of life. Ann Intern Med. 1993;118(8):622-9.

47. Ware J, Kosinski M. SF-36 physical and mental summary scales: a user's manual. Boston: New England Medical Center, The Health Institute; 1994.

48. Ware J, Snow K, Kosinski M, Gandek B. SF-36 health survey, Manual and interpretation guide. Boston: New England Medical Center, The Health Institute; 1993.

49. Guyatt $\mathrm{G}$. Insights and limitations from health-related quality-of-life research. J Gen Intern Med. 1997:12(11):720-1.

50. Shah LC, West P, Bremmeyr K, Savoy-Moore RT. Health literacy instrument in family medicine: the "newest vital sign" ease of use and correlates. J Am Board Fam Med. 2010;23(2):195-203.

51. Hunt K, Weber E, Showstack J, Colby D, Callaham M. Characteristics of frequent users of emergency department. Ann Emerg Med. 2006;48(1):1-8.

\section{Submit your next manuscript to BioMed Central and we will help you at every step:}

- We accept pre-submission inquiries

- Our selector tool helps you to find the most relevant journal

- We provide round the clock customer support

- Convenient online submission

- Thorough peer review

- Inclusion in PubMed and all major indexing services

- Maximum visibility for your research

Submit your manuscript at www.biomedcentral.com/submit
Biomed Central 